\title{
Synaptogenesis in Hippocampal Cultures: Evidence Indicating That Axons and Dendrites Become Competent to Form Synapses at Different Stages of Neuronal Development
}

\author{
Tara L. Fletcher, ${ }^{1}$ Pietro De Camilli, ${ }^{2}$ and Gary Banker ${ }^{3}$ \\ 'Departments of Psychiatry, and Pharmacology and Toxicology, Albany Medical College, Albany, New York 12208, \\ 2Department of Cell Biology and Howard Hughes Medical Institute, Yale University School of Medicine, New Haven, \\ Connecticut 06510, and ${ }^{3}$ Department of Neuroscience, University of Virginia School of Medicine, Charlottesville, Virginia \\ 22908
}

\begin{abstract}
Hippocampal neurons in culture develop extensive axonal and dendritic arbors and form numerous synapses. Presynaptic specializations occur at sites of contact between axons and somata or dendrites but they do not appear until day 3 in culture, even though numerous contacts between cells develop within the first $24 \mathrm{hr}$ (Fletcher et al., 1991). To determine whether this delay in the appearance of presynaptic specializations could be related to maturational events in the presynaptic axon or in the postsynaptic target, "heterochronic" cocultures were prepared by adding newly dissociated neurons to cultures containing mature neurons. The competence of axons to form presynaptic vesicle clusters in response to contact with the somata or dendrites of mature or immature neurons was determined by immunofluorescent staining for synapsin I or synaptophysin. After only $1 \mathrm{~d}$ of coculture, there was a fivefold increase in the number of synapses along the somata and dendrites of the mature neurons, compared to mature neurons cultured alone. If newly dissociated neurons were labeled with a fluorescent dye before coculture, dye-labeled axons frequently were colocalized with presynaptic specializations on mature cells. In contrast, when the axons of mature neurons contacted immature neurons, synapses were first observed only after coculture for $3 \mathrm{~d}$.
\end{abstract}

These results suggest that the axons of hippocampal neurons have the capacity to form presynaptic specializations soon after they emerge, provided they encounter appropriate targets, but that the cell bodies and dendrites of hippocampal neurons are not capable of inducing the formation of presynaptic specializations until they reach a critical stage of maturation.

\footnotetext{
Received Jan. 27, 1994; revised Apr. 18, 1994; accepted May 5, 1994.

This research was supported by NIH Grants NS17112 to G.B., MH45191 to P.D., and BRSG S07RR05394-31 to T.L.F. We thank Dr. Reinhard Jahn for providing synaptophysin antisera, Dr. Lester Binder for antibodies against MAP2, Colleen Fitzgerald and Cindy Trautman for technical assistance with preparation of cell cultures, and Dr. Deanna Benson for critical comments on the manuscript. We also thank Dr. Helen Molinari for her valuable advice and encouragement throughout the course of this work. Portions of this manuscript were submitted by T.L.F. in partial fulfillment of the requirements for the degree of Doctor of Philosophy, Albany Medical Center Graduate School of Health Sciences, Albany, New York.

Correspondence should be addressed to Dr. Gary Banker, Department of Neuroscience, University of Virginia School of Medicine, MR-4, Box 5148, Charlottesville, VA 22908.

Copyright (C) 1994 Society for Neuroscience $0270-6474 / 94 / 146695-12 \$ 05.00 / 0$
}

[Key words: synaptogenesis, hippocampal cell culture, synaptic vesicles, neuronal polarity, presynaptic specialization, immunofluorescence microscopy]

The mechanisms underlying the formation of pre- and postsynaptic specializations are poorly understood, particularly with regard to neurons in the CNS. Electron microscopic studies have provided a description of many of the cytological aspects of synapse formation (Vaughn, 1989; Peters et al., 1991), and tools are now becoming available to examine the synthesis and assembly of many of the important molecular components of synapses (Changeux et al., 1990; Killisch et al., 1991; Craig et al., 1993; Lou and Bixby, 1993; Nastuk and Fallon, 1993; reviewed in Hall and Sanes, 1993), but except at the neuromuscular junction, we have little understanding of the inductive interactions that regulate synaptic assembly. The complexities of the developing nervous system and the technical difficulties involved in studying individual neurons in vivo have hindered progress in this area.

Cell culture offers an obvious alternative approach for analyzing synaptogenesis, and studies of a variety of different types of neurons have already demonstrated the potential of this approach (see, e.g., Burry, 1986; Loffler et al., 1986; O'Brien and Fischbach, 1986; Weiss et al., 1986; Dubinsky, 1989; Nelson et al., 1990; Ryan et al., 1993). Work in our laboratory has focused on studies of cultured hippocampal neurons. Like their counterparts in situ, these neurons develop distinct axons and dendrites and form synapses with one another that exhibit a normal synaptic polarity - axons are predominantly presynaptic and dendrites postsynaptic (Bartlett and Banker, 1984). Using immunostaining to localize synaptic vesicle antigens, synapses can be recognized at the light microscopic level as brightly stained puncta outlining the dendrites and cell bodies of these neurons (Fletcher et al., 1991). Electron microscopic immunocytochemistry has confirmed that these puncta correspond to vesicle clusters within presynaptic specializations (Fletcher et al., 1991). Moreover, it was shown that vesicles within these clusters undergo exo-endocytotic recycling as previously shown for synaptic vesicles in situ (Matteoli et al., 1992). The synaptic relationships that are established in hippocampal cultures are likely to represent types normally present in situ. Pyramidal cells, which constitute the predominant cell type in these cultures, normally establish synapses with one another via Schaffer collaterals, commissural projections, and local recurrent collaterals 
(Shepherd, 1990). GABAergic interneurons, which account for $7 \%$ of the neurons in these cultures, also synapse with one another and with non-GABA cells, and GABAergic synapses form preferentially on cell bodies, as they do in situ (Benson et al., 1994).

In a previous study, we noted that synapsin I and synaptophysin are expressed early in development, and synaptic vesiclecontaining axons contact other cells soon after plating, but the immunoreactive puncta that represent presynaptic specializations were not observed until several days later. Presumably this delay occurs because other maturational events are required before synaptogenesis can begin. Although in this culture paradigm hippocampal neurons serve as both presynaptic elements and postsynaptic targets, we wondered if it might be possible to differentiate maturational processes affecting primarily presynaptic or postsynaptic processes. This report describes an experimental approach to distinguish these possibilities.

The basic paradigm we have used involves the establishment of cocultures containing hippocampal neurons at different stages of maturation. Such "heterochronic" cocultures were prepared by adding newly dissociated hippocampal neurons to cultures that had already been maintained for $4 \mathrm{~d}$, the stage when synapses are just beginning to form. In such cocultures, the immature neurons extended axons and contacted the older neurons within $1 \mathrm{~d}$. Likewise, axons from the older neurons contacted the cell bodies of young neurons within a day. The question, then, was which, if any, of these heterochronic contacts resulted in the formation of synapses, as assessed by the formation of clusters of immunoreactive vesicles. If synaptic terminals were observed on the cell bodies and dendrites of young neurons in heterochronic cocultures, it would demonstrate directly that these neurons had already matured sufficiently as postsynaptic elements to induce vesicle clustering. If a greater number of presynaptic specializations were observed on mature neurons in heterochronic cocultures than in control cultures, it would imply that young axons were capable of forming presynaptic specializations and would suggest that the delay in synaptogenesis that normally occurs in culture is due to the immaturity of postsynaptic elements.

In reality, it may seem likely that the delay in synaptogenesis observed in culture involves the maturation of both pre- and postsynaptic elements, making the outcome of the proposed experiments difficult to interpret. Surprisingly, this was not the case. Our results indicate that, from the beginning, axons are competent to form aggregates of synaptic vesicles in response to contact with mature target cells. In contrast, dendrites and somata of hippocampal neurons become competent to induce vesicle aggregation in the axons that contact them only after they have matured in culture for 3 or $4 \mathrm{~d}$. These observations provide new insights into the cellular interactions underlying synaptogenesis, emphasizing in particular the regulatory role of postsynaptic elements in the formation of presynaptic specializations.

\section{Materials and Methods}

Hippocampal cell cultures. Cell cultures were prepared from hippocampi of 18-d-old fetal rats, as previously described (Banker and Cowan, 1977; Goslin and Banker, 1991). Briefly, hippocampi were dissociated by treatment with trypsin $\left(0.25 \%\right.$ for $15 \mathrm{~min}$ at $\left.37^{\circ} \mathrm{C}\right)$ and trituration with a fire-polished Pasteur pipette. The cells were plated onto poly-L-lysinetreated glass coverslips in MEM with $10 \%$ horse serum at densities ranging from 200 to 16,000 cells $/ \mathrm{cm}^{2}$. After $3-4 \mathrm{hr}$, when the cells had attached to the substrate, coverslips were transferred into dishes containing a monolayer of astroglial cells (Booher and Sensenbrenner, 1972) oriented so that they faced the glia but did not contact them. The cells were maintained in MEM with N2 supplements (Bottenstein and Sato, 1979), ovalbumin (0.1\%), and pyruvate (0.1 mM) (Selak et al., 1985). Cytosine arabinoside $(5 \mu \mathrm{M})$ was added $3 \mathrm{~d}$ after plating to inhibit the proliferation of non-neuronal cells.

Heterochronic cocultures of young and older neurons were prepared by adding newly dissociated hippocampal neurons to cultures containing hippocampal neurons plated $4 \mathrm{~d}$ earlier. Prior to the addition of new cells, the coverslips containing 4-d-old hippocampal neurons were turned face up in their dishes. Three to four hours after the addition of newly dissociated neurons, coverslips were placed cells down into fresh dishes containing glial cells as described above. Cytosine arabinoside $(2.5 \mu \mathrm{M})$ was added $3 \mathrm{~d}$ later. To determine whether mature somata and dendrites could induce presynaptic vesicle aggregation in newly formed axons, freshly dissociated hippocampal neurons were plated at high density $\left(16,000 \mathrm{cell} / \mathrm{cm}^{2}\right)$ on coverslips with a low density $\left(200 \mathrm{cells} / \mathrm{cm}^{2}\right)$ of hippocampal neurons plated $4 \mathrm{~d}$ earlier. To determine whether the somata and newly formed dendrites of neurons at early stages of development in culture can induce the formation of presynaptic vesicle clusters in mature axons, freshly dissociated hippocampal neurons were plated at moderate density $\left(6000 \mathrm{cells} / \mathrm{cm}^{2}\right)$ onto $4-\mathrm{d}$-old cultures containing a dense plexus of axons $\left(16,000\right.$ cells $\left./ \mathrm{cm}^{2}\right)$.

Labeling dissociated cells with diI. In some experiments newly dissociated hippocampal neurons were labeled with diI (1,1'-dioctadecyl3,3,3', $3^{\prime}$-tetramethylindocarbocyanine perchlorate; Molecular Probes, Junction City, OR), a fluorescent carbocyanine dye, prior to plating so that their axons could be identified in cocultures with unlabeled cells. We followed the procedure for labeling dissociated cells described by Honig and Hume (1986), with minor modifications. Cells were suspended in MEM containing 10\% horse serum, HEPES (10 mM), pyruvate $(1.0 \mathrm{~mm})$, and glucose $(0.6 \%)$ and incubated with diI $(40 \mu \mathrm{g} / \mathrm{ml}$ final concentration, diluted from a stock solution of $2.5 \mathrm{mg} / \mathrm{ml}$ in ethanol) in a $37^{\circ} \mathrm{C}$ shaking water bath for $30 \mathrm{~min}$ in the dark. Cells were then collected by centrifugation $(800 \mathrm{rpm}, 5 \mathrm{~min})$, resuspended, and washed three times more with MEM plus $10 \%$ horse serum. After the final centrifugation the pellet was resuspended in warm MEM with N2 supplements ( $\mathrm{pH} 7.3$ ) and the cells were plated at a density of 10,000 cells $/ \mathrm{cm}^{2}$ into dishes containing 4-d-old hippocampal neurons $(6000$ cells $\left./ \mathrm{cm}^{2}\right)$.

Immunofluorescence microscopy. Cultures were fixed for $20 \mathrm{~min}$ with warm 4\% formaldehyde in PBS containing $0.12 \mathrm{M}$ sucrose, permeabilized in $0.3 \%$ Triton X-100 for $5 \mathrm{~min}$ at room temperature, and rinsed in PBS. Fixed, permeabilized cultures were stored for up to $5 \mathrm{~d}$ in PBS containing sodium azide $(0.05 \%)$. Before staining, cells were blocked with $10 \%$ BSA for $1 \mathrm{hr}$ at $37^{\circ} \mathrm{C}$, and then exposed to both primary antibodies (diluted in $1 \%$ BSA/PBS) overnight at $4^{\circ} \mathrm{C}$. The primary antibodies used were affinity-purified rabbit polyclonal anti-synapsin I (1:250) (De Camilli et al., 1979), and AP14, a mouse monoclonal antiMAP2 (1:400) (a gift from Lester Binder, University of Alabama, Birmingham) (Caceres et al., 1986). In some experiments, mouse monoclonal anti-synaptophysin antibodies (1:500) (a gift from Reinhard Jahn, Yale University School of Medicine, New Haven, CT) (Navone et al., 1986) were used for comparison with results obtained using synapsin I immunostaining. After exposure to the primary antibodies, the cultures were rinsed in PBS and incubated for $1 \mathrm{hr}$ at $37^{\circ} \mathrm{C}$ with biotinylated goat anti-rabbit IgG (1:800; Vector Laboratories, Burlingame, $\mathrm{CA})$ and fluorescein-conjugated goat anti-mouse IgG (1:200; Cappel Laboratories, Cochranville, PA). The cultures were then rinsed with PBS and incubated with rhodamine-conjugated avidin (1:1000; Vector Laboratories) for $1 \mathrm{hr}$ at $37^{\circ} \mathrm{C}$. After rinsing with PBS, coverslips were mounted in PBS:glycerol (1:1), containing 0.05\% p-phenylenediamine (Johnson et al., 1981). Cultures were photographed using Kodak Tri-X film, which was developed in Diafine.

When diI was used to label cells, cultures were fixed as described above, but were not treated with Triton X-100, which solubilized diI. We found that exposure to anti-synapsin overnight at $37^{\circ} \mathrm{C}$ was sufficient for immunostaining even in the absence of permeabilization, probably due to fixative-induced damage to the cell surface. After rinsing in PBS, the cultures were exposed to fluorescein-conjugated goat anti-rabbit (1: 200; Cappel Laboratories) at $37^{\circ} \mathrm{C}$ overnight, and then rinsed in PBS and mounted as described above.

Quantitative analysis. Cells for analysis were selected at random, based on predetermined stage coordinates. Cells whose dendritic processes 
intermingled with those of neighboring cells were excluded from the analysis. Older cells were identified as having somata that were 15-20 $\mu \mathrm{m}$ in diameter that gave rise to tapering dendrites brightly stained with anti-MAP2. Immature neurons had distinctly smaller cell bodies (about $10 \mu \mathrm{m}$ diameter) and minor processes that lacked the characteristic taper of dendrites, and were only faintly stained by anti-MAP2. Photographs were prepared of each cell to show its morphology by phase-contrast microscopy and immunostaining for synapsin I and MAP2. To minimize any error associated with the photographic process, the conditions for photography, film development, and printing were kept uniform for all experiments. On average, 30 cells were analyzed at each time point for each experimental condition; each experiment was repeated three limes using separate culture preparations.

From the MAP2 immunostaining we determined the number of dendrites per cell, the total number of dendritic branch points per cell, and the length of each dendrite (using a digitizing pad and SIGMA SCAN software, Jandel Scientific). Prints showing synapsin I localization were used to count presynaptic specializations. We determined both the number of puncta and the proportion of the dendritic tree that was innervated. For these purposes a punctum was taken as a roughly spherical, brightly fluorescent spot juxtaposed to a cell body or dendrite. Previous results have shown that such puncta correspond to presynaptic specializations containing pronounced accumulations of vesicles when examined by electron microscopic immunocytochemistry (Fletcher et al., 1991). The proportion of the dendritic tree that was innervated was determined by measuring the length of dendrite from the cell body to the distalmost punctum and expressing this as a fraction of the overall dendritic length. We also determined the synaptic density along the innervated length, defined as the number of synapsin I puncta per unit length of innervated dendrite. Some caution is needed in interpreting these measurements. While our analysis was confined to developmental times when the overall synaptic density was still low enough that individual puncta were well resolved, it is likely that some closely adjacent puncta were not resolved, leading to an underestimation of synaptic number. Newly formed synapses with few vesicles might also have been missed. Synapses can become functional before significant aggregations of vesicles are detectable by immunofluorescence or electron microscopy (Landmesser and Pilar, 1972; Xic and Poo, 1986; Evers et al., 1989). Thus quantitative methods based on immunofluorescence localization of synaptic vesicles may underestimate the absolute number and density of developing synapses, but should allow a reasonable comparison of the rate at which presynaptic vesicle aggregations form under different experimental conditions.

\section{Results}

Time course of the development of presynaptic specializations

Before undertaking the proposed coculture experiments, it was necessary to obtain accurate baseline data concerning the time course of synaptogenesis. An example of such an experiment is shown in Figure 1, which illustrates hippocampal cultures that had been prepared at a high cell density and maintained for 2 , 4 , and $7 \mathrm{~d}$ in culture. These cultures were double stained to show the distribution of immunoreactive synapsin I and MAP2. Cell-cell contact was evident during the first day in culture, and by day 2 most neurons had established contact with neighboring cells (Fig. $1 A$ ). Despite these numerous contacts, puncta of synapsin I immunoreactivity like those in mature cultures that have been shown to correspond to presynaptic vesicle clusters were not observed (Fig. 1C). At higher magnification, tiny dots of synapsin I immunoreactivity could be detected in the distal portions of axons and axonal growth cones, as described previously (Fletcher et al., 1991), but these were quite distinct from the large, bright puncta that surround the cell bodies and dendrites in mature cultures. At this early stage of development, faint MAP2 immunofluorescence was present throughout the cells with only occasional processes exhibiting "dendrite-like" staining comparable in intensity to that of more mature cells (Fig. 1B).

The first puncta of synapsin I were observed on day 3 or 4 in culture (Fig. $1 D-F$ ). By day 4 , most cells had several puncta of synapsin I along their somata and dendrites (arrows in Fig. $(E-F)$, while a few cells, although similar in overall appearance, still lacked synapsin I puncta (arrowhead in Fig. $1 D-F$ ). By the end of the first week in culture, practically every neuron was outlined by numerous puncta of synapsin I immunoreactivity (Fig. $1 G-I$ ). The dendrites had become longer, exhibited the tapering and branching characteristic of maturing dendrites, and were densely covered by synapsin I puncta (Fig. 1G-I).

To determine how the density of neurons in the culture influenced the rate of synaptogenesis, we compared the number of synapsin I puncta on neurons from cultures that had been preparcd at different plating densities, from very low (200 cells/ $\left.\mathrm{cm}^{2}\right)$ to moderate $\left(6000\right.$ cells $\left./ \mathrm{cm}^{2}\right)$ and high density $(16,000$ cells $/ \mathrm{cm}^{2}$ ). The results are summarized in Figure 2 . The rate of formation of presynaptic specializations was clearly density dependent. At the highest density more than 80 synapses had formed on each cell by day 7 , whereas at the lowest density fewer than 10 synapses had formed. This is as expected, since the density of afferent axons capable of forming presynaptic specializations depends on cell density. At early stages in lowdensity cultures, when puncta were infrequent, it was common to observe cells that had terminals along only one or two of their dendrites, as if some dendrites were contacted by presynaptic axons and others were not. It was impossible to follow synaptogenesis quantitatively beyond $7 \mathrm{~d}$ because the dendrites overlapped extensively and puncta were too close together to count accurately. Nevertheless, it was clear from inspection that the density of puncta continucd to increase for at lcast 2 wecks after plating.

At each plating density there was a distinct lag period of 3$4 \mathrm{~d}$ before the first presynaptic specializations were observed. After this lag period, the number of synapses increased rapidly. This was true even in high-density cultures where numerous contacts between cells formed within $1 \mathrm{~d}$ after plating. These results suggest that hippocampal neurons must attain a certain degree of maturation before synaptogenesis can proceed.

The development of presynaptic specializations in cocultures of neurons at different stages of development

To assess whether axons formed presynaptic specializations with less delay if they contacted more mature postsynaptic targets, freshly dissociated neurons were added to very-low-density cultures containing hippocampal neurons that had been maintained for $4 \mathrm{~d}$. In order to discriminate synapses from the young axons, cultures were initially plated at a very low density so that the number of endogenous synapses would be small, and then a high density of freshly dissociated neurons was added. We compared the number of puncta of synapsin I on mature neurons after 5,6 , and $7 \mathrm{~d}$ in low-density cultures with that on mature neurons of the same age that had been cocultured with younger neurons for 1, 2, and $3 \mathrm{~d}$, respectively. The difference in the number of presynaptic specializations in the two sets of cultures was striking (Fig. 3). As expected from the results described above, few synapses formed during the first week on neurons in very-low-density cultures (Fig. $3 A-C$ ). At 5 and $6 \mathrm{~d}$ more than half of the cells in low-density cultures lacked synapsin Ipositive presynaptic vesicle clusters along their dendrites. In the case of cells that exhibited synapses, puncta of synapsin I were often present along some dendrites but not others (Fig. 3D-F).

In distinct contrast to the neurons in these low-density cul- 

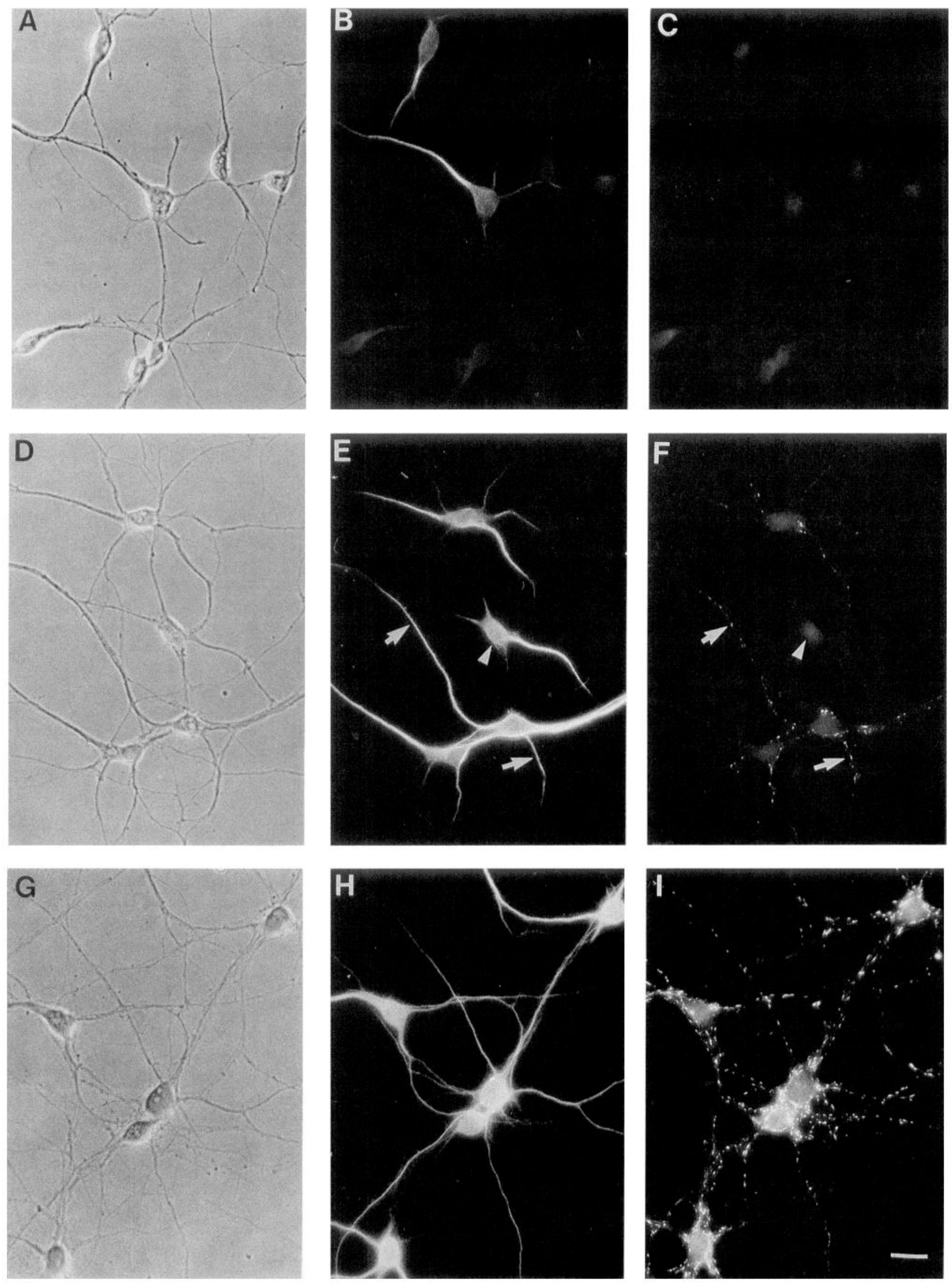
tures, coculture of 4-d-old neurons with newly dissociated neurons for even $1 \mathrm{~d}$ resulted in the formation of numerous synapsin I-positive puncta along their cell bodies and dendrites (Fig. 3GI). After $2 \mathrm{~d}$ of coculture, puncta of synapsin I outlined the entire dendritic tree of the older neurons, now $6 \mathrm{~d}$ old (Fig. 3J$L$ ). We almost never observed individual dendrites that lacked synapsin I puncta. In marked contrast, the cell bodies and developing dendrites of the younger neurons in these cultures were not contacted by puncta (asterisks in Fig. $3 G-I$ ).

Figure 4 illustrates the results of a quantitative comparison of the number of synapses per cell in low-density cultures and cocultures from a single representative experiment. At every time point, there were many more synapses per old cell in the cocultures (significant at $p<0.001$, Mann-Whitney $U$ test). Perhaps the most striking difference between the two cultures concerned the number of cells receiving no synapses at all. In the cocultures, only 5 of 27 old cells lacked puncta of synapsin I after $1 \mathrm{~d}$ of coculture, compared with 27 of the 35 cells sampled in the low-density controls. By the third day of coculture, there was a sixfold increase in the median number of synapses per cell, compared with controls. Comparable results were observed in two other experiments (data not shown). A similar increase in the number of puncta per cell and in the fraction of cells innervated was also observed when antibodies against synaptophysin, another vesicle protein, were used to identify presynaptic specializations, although these results were not quantified.

These results suggest that axons are capable of forming presynaptic specializations soon after they emerge, provided they encounter appropriately mature synaptic targets. They also suggest that the somata and dendrites may not become competent to induce presynaptic vesicle aggregations within axons until they reach a critical period in their development. To explore this second possibility further, we assessed the capacity of more mature axons to form presynaptic specializations in response to contact with the cell bodies of hippocampal neurons that had been cultured for only $1 \mathrm{~d}$. Freshly dissociated ncurons werc added to 4-d-old cultures containing a high density of mature neurons, and then stained for synapsin I and MAP2 $1 \mathrm{~d}$ later. The cell bodies and developing dendrites of the 1-d-old neurons could be readily distinguished by their small size and weak MAP2 staining. Although such cultures contained an extremely dense plexus of axons arising from the 4-d-old cells, puncta were never observed on the somata of immature neurons in these cultures (data not shown).

The coincidence of puncta of synapsin I with sites where axons of immature neurons contact more mature targets

The most likely explanation for the increase in the number of synapses along mature neurons in cocultures with immature neurons is that the axons of immature neurons formed presynaptic specializations with the older neurons in the cocultures. To demonstrate directly that young neurons are capable of forming presynaptic specializations, we labeled neurons with diI im-

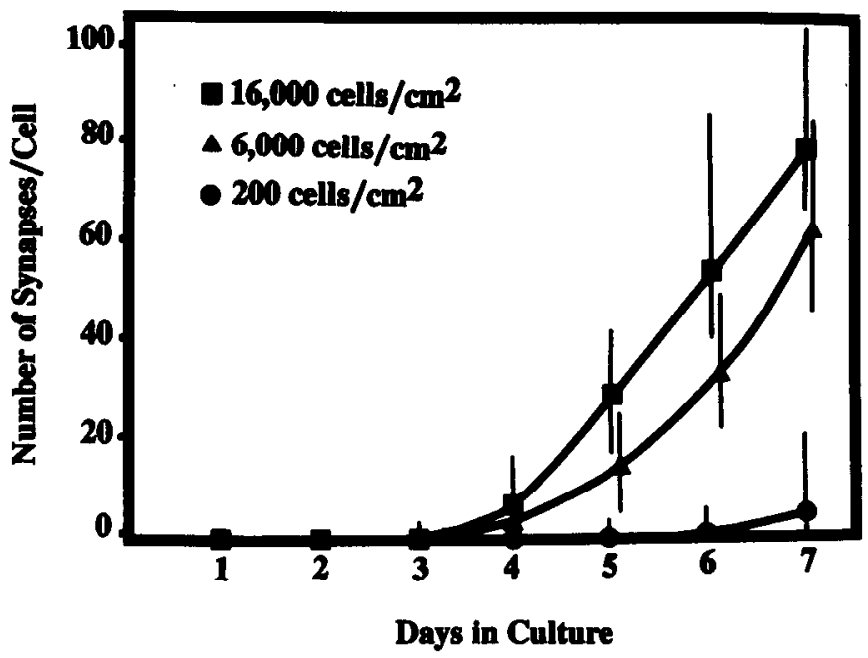

Figure 2. The time course of formation of synapses (puncta of synapsin I) on hippocampal neurons in culture at low, moderate, and high plating densities $\left(200,6000\right.$, and 16,000 cells $/ \mathrm{cm}^{2}$, respectively). No puncta were evident before $3 \mathrm{~d}$ in culture at any plating density. In the highdensity cultures, where many neurons contact one another by day 1 , a small number of puncta were first observed on a few cells on day 3. In moderate- and low-density cultures, puncta first appeared on days 4 and 5 , respectively. After their initial appearance, the number of synapsin I puncta per cell increased rapidly over the next several days. Data points represent medians and error bars represent the interquartile ranges. The sample size ranged from 27 to 53 cells.

mediately after dissociation, and then plated them into cultures containing 4-d-old cells. These cultures were fixed 1 or $2 \mathrm{~d}$ later and immunostained to determine if some of the synapsin Icontaining puncta colocalized with dye-labeled axons. An example from such an experiment is illustrated in Figure 5. Young neurons and their processes were heavily labeled with dil, while the cell bodies and processes of the older neurons were not (large astcrisks in Fig. 5A-F). Many synapsin I-containing puncta were observed at sites where diI-labeled axons contacted unlabeled older neurons (arrows in Fig. 5). Other puncta were clearly associated with unlabeled axons presumably from mature cells (arrowheads in Fig. 5). Dye-labeled somata were never innervated. These results are just those predicted if a significant proportion of the synapses in the cocultures derive from young axons, although fasciculation of unlabeled axons with dil-labeled axons could also account for some of the double-labeled puncta we observed.

\section{The distribution of synapses along the dendritic tree}

We have presented evidence that there is a large and rapid increase in the total number of synapses on neurons in lowdensity cultures following the addition of a high density of newly dissociated neurons. This increase could reflect innervation of a greater proportion of the dendritic tree of the mature neurons, or an increase in the density of synapses within innervated regions

\footnotetext{
Figure 1. Phase-contrast $(A, D, G)$ and fluorescence micrographs showing the distribution of microtubule-associated protein 2 (MAP2) $(B, E, H)$ and synapsin $\mathrm{I}(C, F, I)$ in hippocampal neurons after $2 \mathrm{~d}(A-C), 4 \mathrm{~d}(D-F)$, and $7 \mathrm{~d}(G-I)$ in culture at high plating density $\left(16,000\right.$ cells/cm $\left.{ }^{2}\right)$. On day 2 , axons, which establish initial contacts with neighboring cells by day 1 , had developed a network of fibers between cells $(A)$, but had not formed puncta of synapsin I $(C)$. On day 4 , the dendrites of many neurons were longer and contained bright MAP2 staining $(E)$. MAP2 was evident in the cell body and dendrites but was absent from axons $(E, H)$. Brightly fluorescent synapsin I puncta were present in axons where they contacted the dendrites and somata of some cells (arrows in $E$ and $F$ ), but not others (arrowheads in $E$ and $F$ ). By day 7 practically every neuron was lined by puncta of synapsin I (I). Photographic exposure time appropriate to mature cultures. Scale bar, $10 \mu \mathrm{m}$.
} 

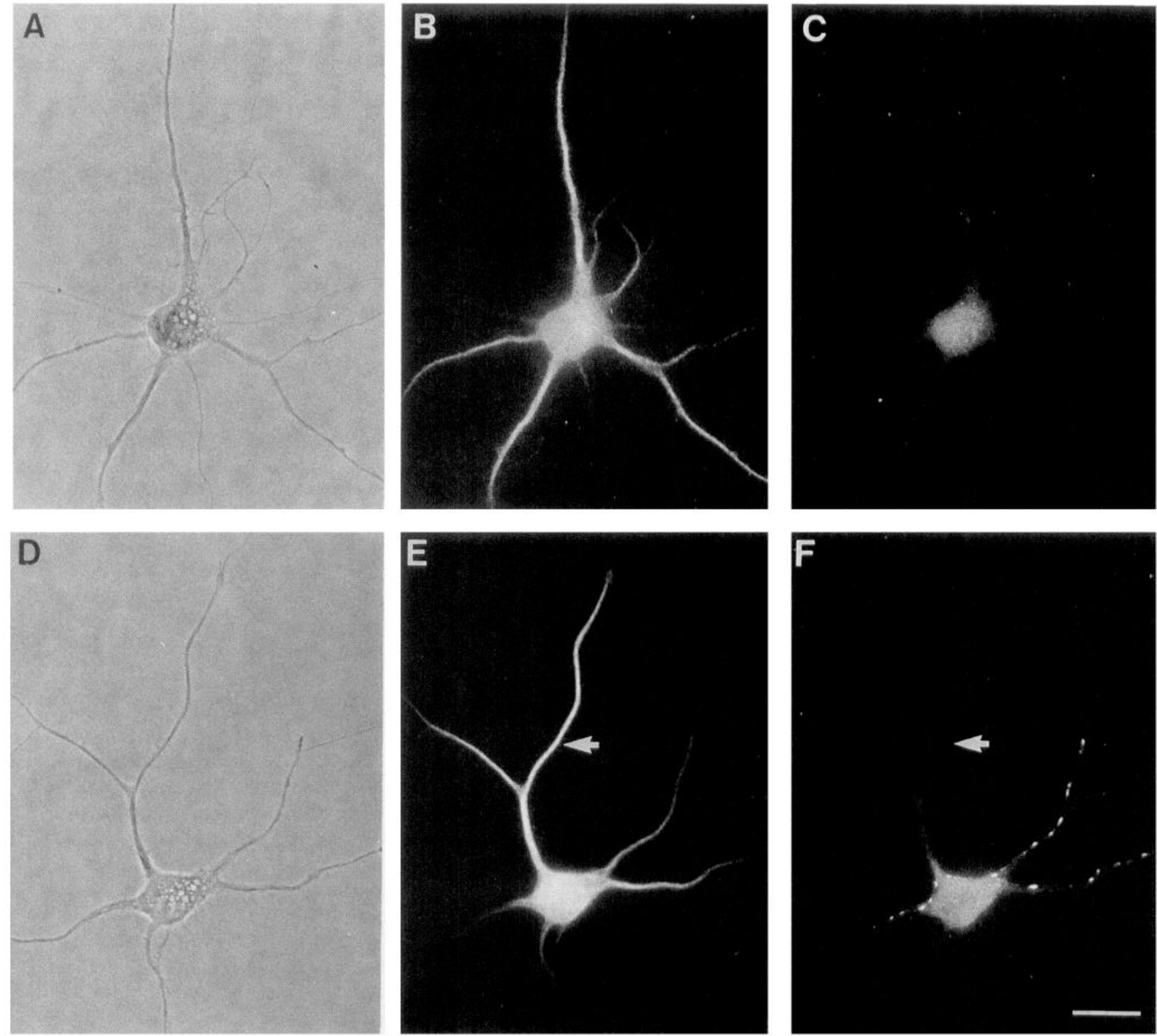

Figure 3. Phase-contrast $(A, D, G, J)$ and fluorescence micrographs showing the distribution of MAP2 $(B, E, H, K)$ and synapsin $I(C, F, I, L)$ in low-density hippocampal cultures $(A-F)$ and in cocultures $(G-L)$ on day $5(A-C$ and $G-I)$ and day $6(D-F$ and $J-L)$. Cocultures were established by adding newly dissociated hippocampal neurons to low-density hippocampal cultures on day 4 in culture. Many neurons in the 5 -d-old lowdensity cultures entirely lacked synapsin I puncta along their cell bodies and dendrites $(C)$, which could be visualized by MAP2 staining $(B)$. In

of the dendrite, or both. Because dendritic growth could itself be stimulated by plating neurons at a higher density, it is also possible that the increase in the number of synapses per cell could be accounted for simply by an increase in the length of the dendritic surface of postsynaptic cells in the cocultures. To evaluate these possibilities we determined the length of the dendrites that were innervated (defined as the distance from the cell body to the distalmost punctum of synapsin I on each dendrite) and the synaptic density within innervated regions (the number of synapses per unit length of innervated dendrite). In calculating average synaptic density, uninnervated dendrites were excluded from analyses. The results of such a quantitative analysis are summarized in Figure 6. The percentage of total length of the dendritic tree that was innervated was four- to sixfold higher for cells in the cocultures than in the low-density cultures
( $p<0.001$, Mann-Whitney $U$ test; see Fig. $6 A$ ). The density of puncta along the dendrites was also $20-35 \%$ higher along the dendrites of cells in the cocultures ( $p<0.005$ after $2 \mathrm{~d} ; p<$ 0.001 after $3 \mathrm{~d}$; see Fig. $6 B$ ). On day $5,1 \mathrm{~d}$ after the addition of newly dissociated neurons, the increase in synaptic number primarily reflected an increase in the number of dendrites being innervated, while on subsequent days an increase in synaptic density was also apparent.

The dendritic morphology of the same cells was also analyzed from MAP2 staining. We determined the number of dendrites, the number of dendritic branch points, and the total length of the dendritic tree for each cell. There was no significant difference in the number of dendrites per cell at any time after coculture with newly dissociated neurons. We did detect small, but significant, increases in the total length of the dendritic tree 

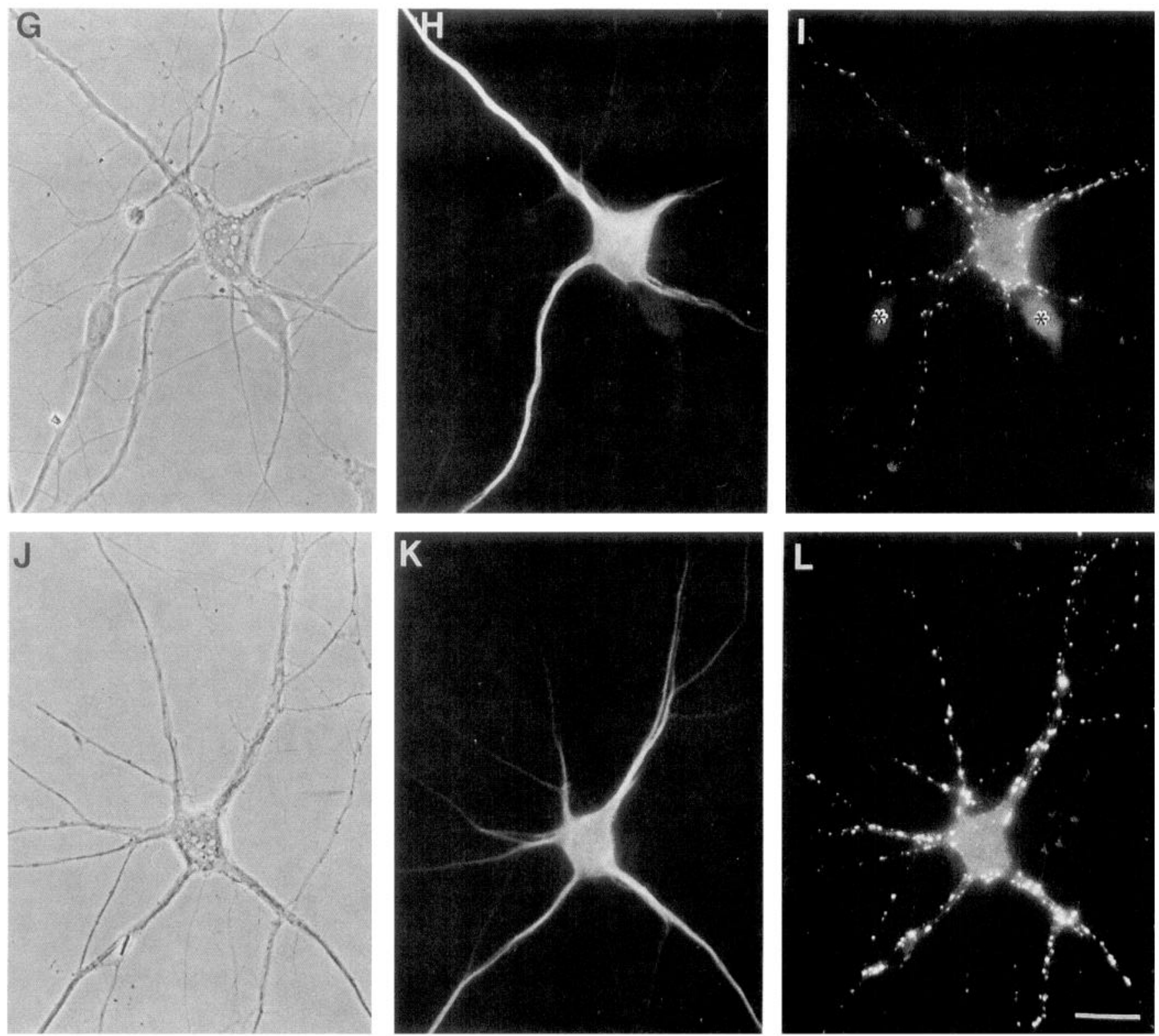

6-d-old low-density cultures a few cells had puncta along some of their dendrites $(E$ and $F)$ but not others (arrows in $E$ and $F$ ). Mature cells in cocultures had numerous bright synapsin I puncta along their cell bodies and dendrites on day $5(G-I)$ and day $6(J-L)$. Immature neurons in cocultures did not have puncta along their surfaces (asterisks in I). Scale bar, $10 \mu \mathrm{m}$.

(Fig. $6 C$ ) and in the number of dendritic branches per cell (data not shown) after $3 \mathrm{~d}$ of coculture. These findings are consistent with previous data from this laboratory showing that dendritic branching and dendritic length are increased in cultures prepared at higher plating densities (Banker and Waxman, 1988). However, this increase in potential postsynaptic area neither was large enough nor occurred early enough to contribute significantly to the increased number of synapses observed in the cocultures.

\section{Discussion}

\section{Synapse formation in heterochronic cocultures}

The present study was designed to determine when during their development in culture hippocampal axons become competent to form presynaptic vesicle aggregations, and when their somata and dendrites become competent to induce these aggregations within axons. Figure 7 summarizes our results. In mature cultures, the axons of hippocampal neurons form presynaptic specializations at sites of contact with dendrites or cell bodies (Fig. $7 A$, right). Synapses never form between "immature" hippocampal neurons (prior to day 4 in culture) despite numerous contacts (Fig. $7 A$, left). When newly dissociated neurons are plated onto cultures that are already forming synapses with one another, we never observed synaptic terminals on the somata or processes of the young neurons, suggesting that immature somata and dendrites cannot induce formation of presynaptic specializations even by competent axons (Fig. $7 B$, left). However, when a high density of freshly plated neurons was added to a low-density culture of 4-d-old cells, we observed a marked increase in presynaptic specializations, when compared with 


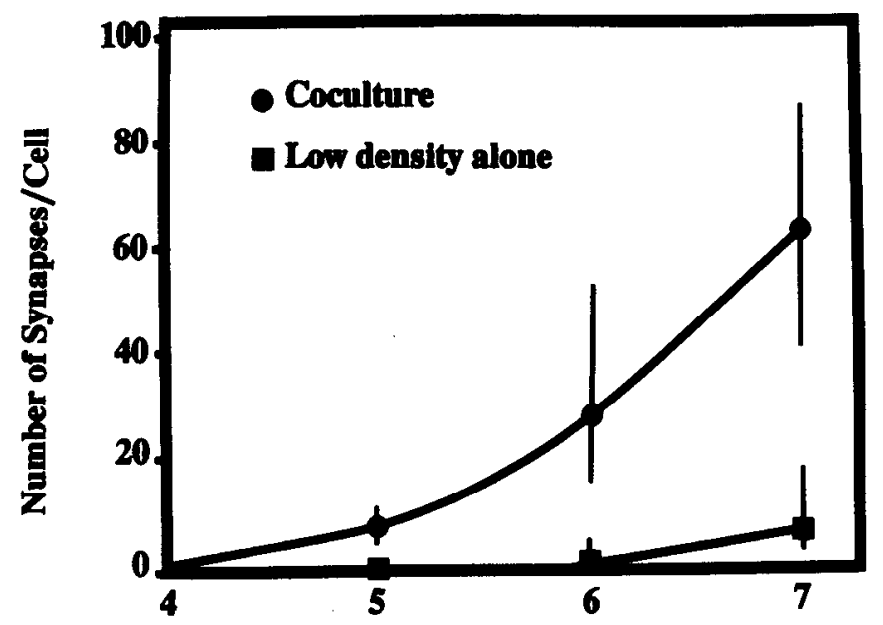

Days in Culture

Figure 4. The number of synapses on mature neurons (synapsin I puncta per cell) in low-density cultures $\left(200 \mathrm{cells} / \mathrm{cm}^{2}\right)$ and in cocultures on days 5, 6, and 7 after initial plating. Only $1 \mathrm{~d}$ after the addition of cells to the cocultures the number of synapses per cell was significantly greater than in the low-density cultures. This difference increased during the next $2 \mathrm{~d}$ in culture (Mann-Whitney rank sum test, $p<0.001$ ). Data points represent medians and error bars represent the interquartile ranges. Sample size ranged from 15 to 53 cells. The result illustrated is from a single experiment. Comparable results were obtained in two other experiments and in cultures stained with anti-synaptophysin.

control low-density cultures of the same age. We interpret this as evidence that the axons of the freshly plated neurons are competent to form synapses, provided that they contact suitable postsynaptic sites (Fig. $7 B$, right).

Might it be that in heterochronic cocultures the young neurons, rather than themselves forming presynaptic specializations, simply caused the mature neurons to form more synapses with each other? Perhaps some trophic effect due to the higher neuronal density induced the older axons to grow more extensively, to branch more rapidly, or to form more puncta along the dendrites they contacted. In order to demonstrate directly that young axons form presynaptic specializations when they contact mature postsynaptic cells, freshly dissociated cells were labeled with diI before being cocultured with mature neurons. Many synapsin I-labeled puncta were observed at sites where dil-labeled axons contacted mature cells. While fasciculation between young and old axons undoubtedly occurs, the frequency with which we observed colocalization of synapsin I and diI staining strongly argues that many of the presynaptic specializations observed in heterochronic cocultures derive from young axons. A priori, it also seems unlikely that a trophic effect could account for as large an increase in the rate of formation of presynaptic specializations as we observed. Assuming a trophic effect on axonal growth and branching, one would have to assume that the presence of additional cells induced the axons of the older cells to grow five times longer in a single day than they had in the 4 preceding days combined. Assuming a trophic effect that primarily enhanced the rate at which existing axons formed presynaptic specializations, one would expect a pronounced increase in the density of puncta along the dendrites that were contacted by existing axons. Instead, the increase in synaptic number at early times primarily reflected an increase in the number of dendrites innervated, as if there were simply more competent axons present; the density of synapses along innervated dendrites increased only slightly at the time points we analyzed. We believe that, taken together, the evidence strongly favors the conclusion that the increased number of presynaptic specializations was primarily the result of the formation of clusters of synaptic vesicles within the newly formed axons of the young neurons.

\section{The timing of synapse formation in culture and in situ}

The finding that perikarya and dendrites are initially not able to induce the formation of presynaptic vesicle clusters in axons offers an explanation for the delay that occurs in hippocampal cultures between the first axosomatic and axodendritic contacts and the formation of presynaptic specializations. Possible parallels have been described previously, both in culture and in situ. For example, Blakemore and Molnar (1990; Molnar and Blakemore, 1991) have investigated the timing of the innervation of visual cortex by thalamic axons in explant cultures. They found that when explants of E16 rat thalamus are cocultured with explants of occipital cortex from neonatal rats, LGN axons grow past the middle cortical plate, where the majority of thalamic fibers normally terminate, without forming terminal arborizations. But when E16 LGN is cultured with occipital cortex explants prepared from older animals ( $\geq 5 \mathrm{~d}$ old), thalamic axons lose their growth cones and ramify within the appropriate layer, suggesting that more mature postsynaptic targets express a retrograde signal that encourages thalamic axons to arborize and terminate. A similar phenomenon may occur in situ. There is often a delay of several days between the arrival of afferent fibers and the formation of synapses (Kornguth et al., 1968; Hinds and Hinds, 1976). At least in some cases the delay appears to involve maturation of the postsynaptic targets. For example, granule cell axons contact both Purkinje cells and stellate cells during the first postnatal week, but form synapses with Purkinje cells several days earlier than with stellate cells (Larramendi, 1969). It is tempting to speculate that such a differential expression of synaptic receptivity may help direct the establishment of appropriate connections during neural ontogeny.

It is important to note that while synaptogenesis may require that postsynaptic elements attain a certain level of maturation, this normally occurs at a relatively early stage of dendritic growth. In hippocampal cultures dendritic growth and synaptogenesis begin at about the same time and both continue for weeks. In situ, synapses on dendritic growth cones are a common fcature of development (Skoff and Hamburger, 1974; Vaughn et al., 1974; Vaughn, 1989).

Our results also show that presynaptic vesicle clusters can form rather rapidly - in $24 \mathrm{hr}$ or less from the time competent pre- and postsynaptic partners contact each other. This is also consistent with several previous results. For example, in cultures of Xenopus embryonic spinal neurons and myotomal muscle cells, the formation of small clusters of synaptic vesicles near the presynaptic membrane was detected by electron microscopy 6-12 hr after initial contact (Buchanan et al., 1989). In cocultures of embryonic rat spinal cord and superior cervical ganglion neurons, synapses were detected within $24 \mathrm{hr}$ following contact (Rees et al., 1976). Vesicle aggregation can occur even more rapidly in situ. During development of the spinal cord of Xenopus, vesicle clusters closely apposed to the axonal membrane appear to form in only 1 or $2 \mathrm{hr}$ (Hayes and Roberts, 1973). Finally, it should be noted that aggregation of vesicles sufficient 

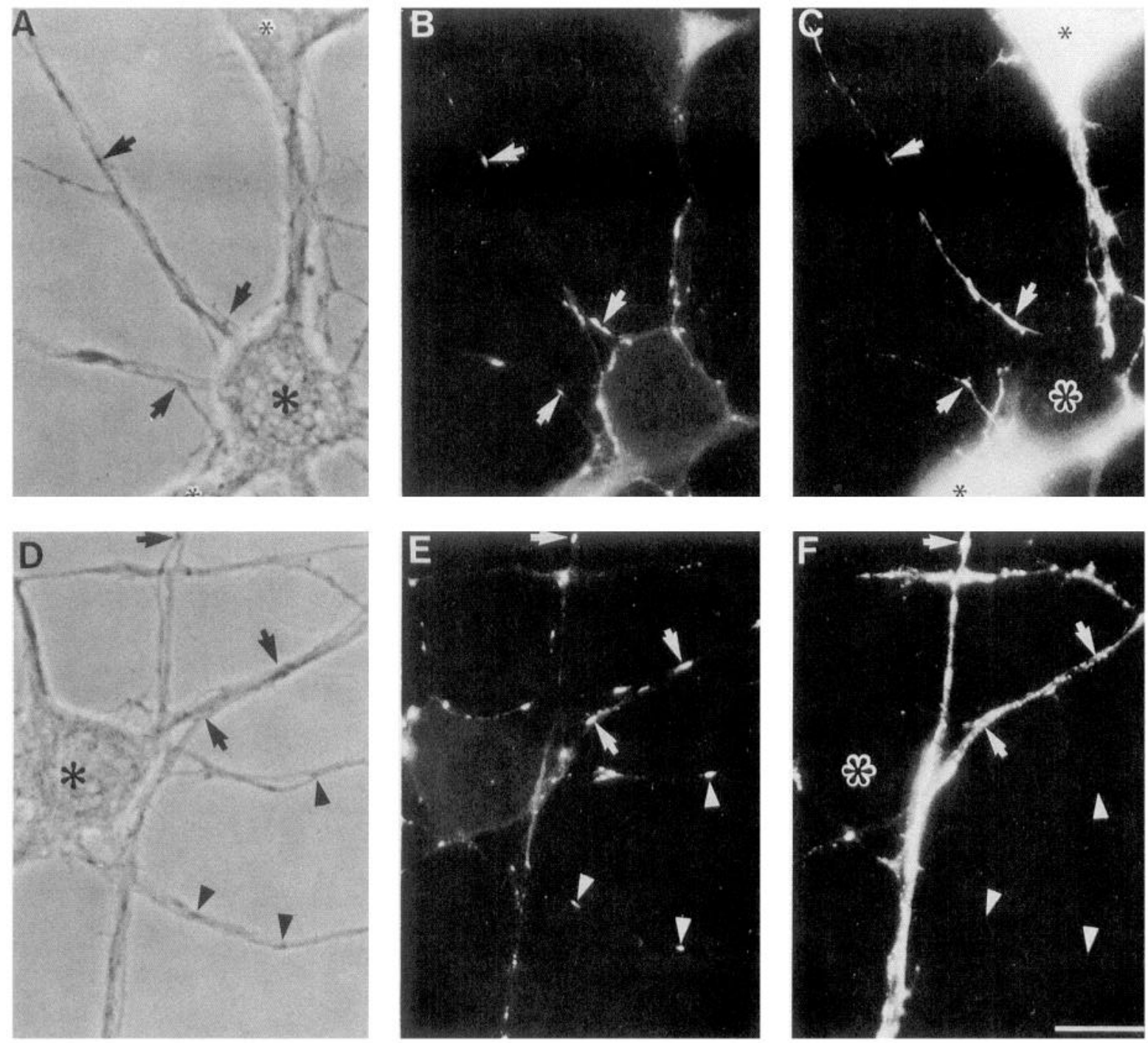

Figure 5. Phase-contrast $(A, D)$ and fluorescence micrographs showing the distribution of synapsin $\mathrm{I}(B, E)$ and diI $(C, F)$ in cocultures prepared by adding diI-labeled hippocampal neurons to 4-d-old hippocampal cultures of moderate density. One day after the establishment of the coculture, the cell bodies and processes of diI-labeled neurons were intensely fluorescent (small asterisks in $A$ and $C$ ), while the older neurons were unlabeled (large asterisks in $A$ and $C$ ). Many synapsin I puncta colocalized with dil-labeled processes (arrows in $A-F$ ). Other puncta were formed along processes that were not dil labeled (arrowheads in $D-F$ ). Scale bar, $10 \mu \mathrm{m}$.

to form large synapsin I-immunoreactive puncta may occur well after the formation of functional synapses, as detected physiologically (Xie and Poo, 1986; Evers et al., 1989).

\section{The development of polarity and synaptic competency}

We have argued previously that in hippocampal cultures the development of polarity, as defined by the formation of two distinct types of processes that differ in structure and function, occurs in at least two phases. From the earliest time that the axon can be identified (at developmental stage 3), it already displays its unique shape, growth properties, and molecular composition. Although the processes from which the dendrites will arise are also present at this stage, it is only some days later (at developmental stage 4) that they begin to elongate and acquire their characteristic morphological and molecular identity. Axonal markers such as GAP-43, L1, and synaptic vesicles are selectively concentrated in the axon at stage 3 of development, but dendritic markers such as $\mathrm{MAP} 2, \mathrm{GABA}_{\mathrm{A}}$ receptors, and AMPA-selective glutamate receptors become restricted to the somatodendritic domain only during stage 4 (Caceres et al., 1986; Dotti et al., 1988; Goslin et al., 1989: Fletcher et al., 1991; Killisch et al., 1991; Craig et al., 1993; Van den Pol and Kim, 1993). Our results indicate that synaptic competence may also emerge in two stages that roughly parallel the developmental stages defined by morphology and molecular compartmentation. Presynaptic competence is apparently achieved with the establishment of the axonal domain (developmental stage 3), while postsynaptic competence arises during the differentiation of the dendritic domain (developmental stage 4).

The reasons why synaptic competence should arise in two stages are not apparent. While it is obvious that synapses cannot develop on dendrites that have not yet formed, the somata and proximal dendrites of mature hippocampal neurons are highly innervated and these regions of the cell receive many axonal contacts as early as $1 \mathrm{~d}$ in culture. Perhaps this plays some role 

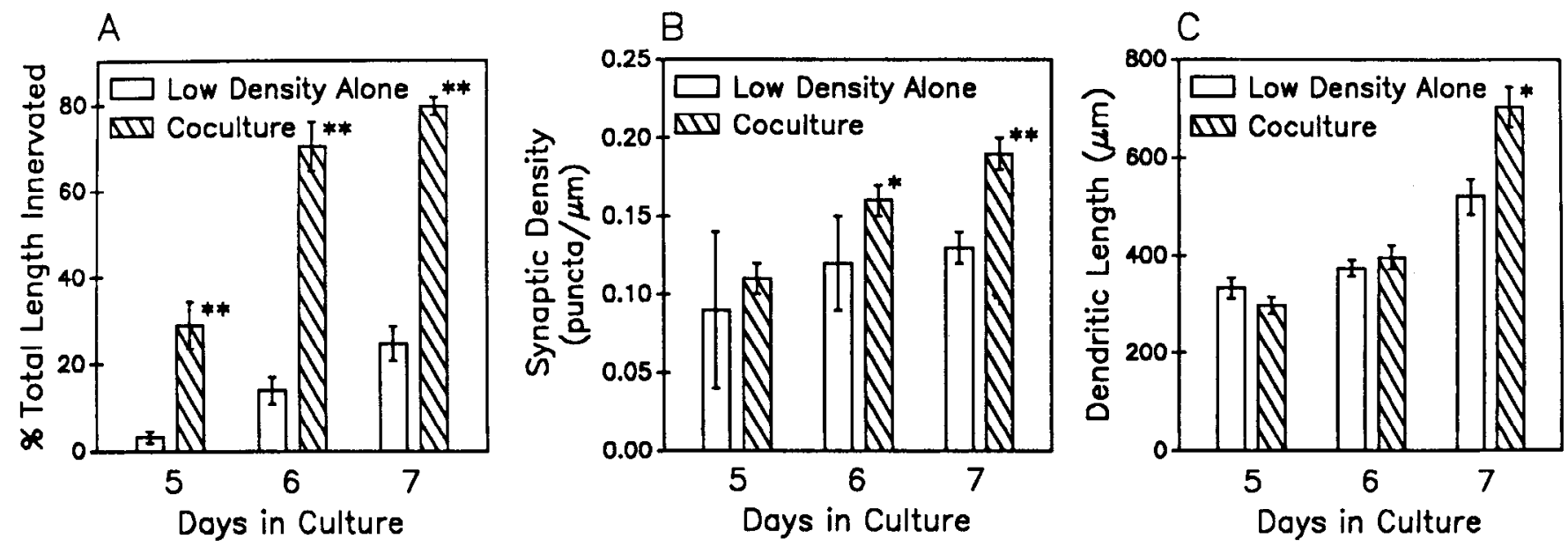

Figure 6. Analysis of percentage of total dendritic length innervated $(A)$, the synaptic density $(B)$, and the total dendritic length $(C)$ in low-density hippocampal cultures and cocultures on days 5,6 , and $7 . A$ shows the percentage of the total dendritic length that is innervated (innervated length was measured from the most distal puncta on each dendrite to the cell body). Cells in the cocultures had significantly more of their dendritic tree lined with synapsin I puncta. $B$ shows the synaptic density (the number of puncta per micrometer of dendrite). There were more puncta per unit length of innervated dendrites in the cocultures than in the low-density cultures at each time point. These differences are significant on days 6 and $7(p<0.005$ and $p<0.001$, respectively). Cells without puncta were not included in the analysis for $A$ and $B$. $C$ compares the total dendritic length (in micrometers) in the two cultures. A slight but significant increase in the length of the dendritic tree of cells in the cocultures was detected after $7 \mathrm{~d}(p<0.005)$. Data are presented as the mean and SEM, and represent sample sizes ranging from 7 to 53 .

in limiting the physiological interactions that can occur during early phases of neuronal differentiation.

\section{Molecular mechanisms underlying the formation of presynaptic specializations}

Our studies of synapse formation in hippocampal cultures emphasize the importance of interactions between target cells and afferent axons in initiating the formation of presynaptic specializations. We have shown previously that distinct aggregates of vesicles develop preferentially at sites of contact between axons and appropriate postsynaptic targets, somata or dendrites (Fletcher et al., 1991). They seldom occur at sites where axons contact each other or contact glial cells. Beyond this, the density of GABAergic synapses is greater on cell somata than on dendrites (Benson et al., 1994). The present results show that axons, which are themselves competent to form presynaptic special- izations, do so only when they contact postsynaptic targets of sufficient maturity.

All of these findings raise questions concerning the molecular signals that govern where presynaptic specializations form and how they develop. Considerable progress has been made in identifying anterograde signals derived from axons that induce the formation of postsynaptic sites and in elucidating the postsynaptic mechanisms that lead to receptor clustering and to other aspects of the differentiation of the postsynaptic site (Hall and Sanes, 1993). In contrast, much less is known about the processes occurring within the presynaptic cell that lead to the differentiation of presynaptic specializations or about the retrograde signals that may regulate these events. Indirect evidence suggests that synapsins may play a role in vesicle clustering, perhaps by mediating interactions between synaptic vesicles and the actin cytoskeleton (Bahler and Greengard, 1987; Benfenati
Figure 7. A diagram summarizing our observations concerning the formation of presynaptic specializations in conventional and heterochronic hippocampal cultures. $A$, In conventional cultures, presynaptic specializations are not observed early in development (left), when immature axons contact immature target cells, but in older cultures numerous presynaptic specializations occur at sites of contact between mature axons and target cells (right). $B$, In heterochronic cocultures, presynaptic specializations do not form at sites of contact between mature axons and immature postsynaptic targets (left), but do form when the axons of immature neurons contact mature postsynaptic targets (right).
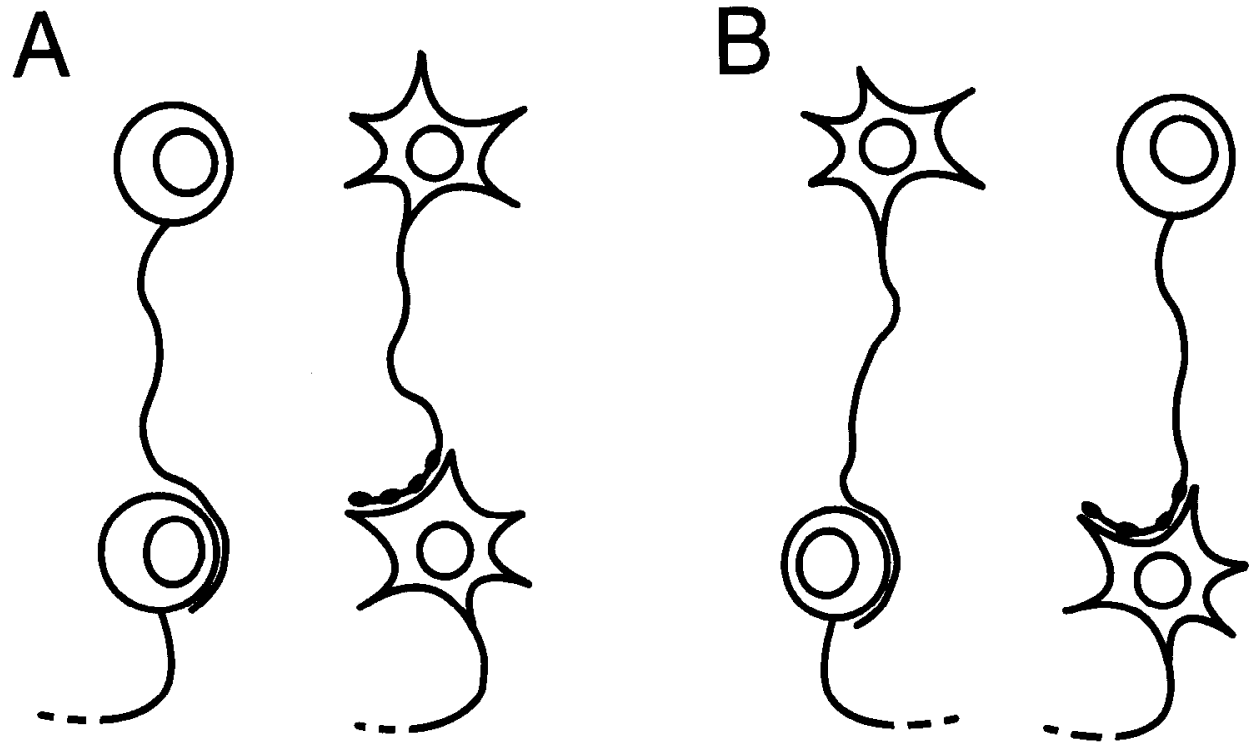
et al., 1992). Consistent with this possibility, Han et al. (1991) have shown that overexpression of synapsins in NG108-15 neuroblastoma $\times$ glioma cells can lead to the formation of clusters of synaptic vesicles. Several studies indicate that the retrograde signaling process that normally governs the localization of presynaptic specializations can be "short-circuited." Contact with a polylysine-coated bead can induce the formation of presynaptic specializations (Burry et al., 1986; Peng et al., 1987), and in cultures from the striatum (Weiss et al., 1986), dorsal root ganglion (Lah and Burry, 1988), and cerebellum (T. Fletcher, unpublished observations), vesicle aggregations sometimes form in the absence of contacts with appropriate postsynaptic partners. The present findings indicate that in hippocampal cultures axons acquire the machinery necessary for vesicle clustering early in their development, and that the timing of synapse formation is determined by signals arising from their postsynaptic targets.

In the heterochronic cocultures described here, synapses form relatively rapidly and synchronously because mature postsynaptic target cells are present from the outset. This paradigm could prove useful in elucidating the retrograde signaling mechanisms that regulate the formation of presynaptic specializations.

\section{References}

Baas PW, Black MM, Banker GA (1989) Changes in microtubule polarity orientation during the development of hippocampal neurons in culture. J Cell Biol 109:3085-3094.

Bahler M, Greengard P (1987) Synapsin I bundles F-actin in a phosphorylation-dependent manner. Nature 326:704-707.

Banker GA, Cowan WM (1977) Rat hippocampal neurons in dispersed cell culture. Brain Res 126:397-425.

Banker GA, Waxman AB (1988) Hippocampal neurons generate natural shapes in cell culture. In: Intrinsic determinants of neuronal form and function (Lasek RJ, Black MM, eds), pp 61-82. New York: Liss.

Bartlett WP, Banker GA (1984) An electron microscopic study of the development of axons and dendrites by hippocampal neurons in culture. II. Synaptic relationships. J Neurosci 4:1954-1965.

Benfenati F, Valtorta F, Chieragatti E, Greengard P (1992) Interaction of free synaptic vesicle-bound synapsin I with F-actin. Neuron 8:377386.

Benson DL, Watkins FH, Steward O, Banker G (1994) Characterization of GABAergic neurons in hippocampal cell cultures. J Neurocytol 23:279-295.

Blakemore C, Molnar Z (1990) Factors involved in the establishment of specific interconnections between thalamus and cerebral cortex. Cold Spring Harbor Symp Quant Biol 55:491-504.

Booher J, Sensenbrenner M (1972) Growth and cultivation of dissociated neurons and glial cells from embryonic chick, rat, and human brain in flask cultures. Neurobiology 2:97-105.

Bottenstein JE, Sato GE (1979) Growth of a rat neuroblastoma cell line in serum-free supplemented medium. Proc Natl Acad Sci USA 76:514-519.

Buchanan J, Sun Y, Poo M (1989) Studies of nerve-muscle interactions in Xenopus cell culture: fine structure of early functional contacts. J Neurosci 9:1540-1554.

Burry RW, Raymond HH, Matthew WD (1986) Presynaptic elements formed on polylysine-coated beads contain synaptic vesicle antigens. J Neurocytol 15:409-419.

Caceres A, Banker G, Binder L (1986) Immunocytochemical localization of tubulin and microtubule-associated protein 2 during the development of hippocampal neurons in culture. J Neurosci 6:714 722.

Changeux JP, Babinet C, Bessereau JL, Bessis A, Cartaud A, Cartaud J, Daubas P, Devillers-Tiery A, Duclert A, Hill JA, Jasmin B, Klarsfeld A, Laufer R, Nghiem HO, Piette J, Roa M, Salmon AM (1990) Compartmentalization of acetylcholine receptor gene expression during development of the neuromuscular junction. Cold Spring Harbor Symp Quant Biol 55:381-396.

Craig AM, Blackstone CD, Huganir RL, Banker G (1993) The dis- tribution of glutamate receptors in cultured rat hippocampal neurons: postsynaptic clustering of AMPA-selective subunits. Neuron 10:10551068.

De Camilli P, Ueda T, Bloom FE, Battenberg E, Greengard P (1979) Widespread distribution of protein $I$ in the central and peripheral nervous systems. Proc Natl Acad Sci USA 76:5977-5981.

Dotti CG, Sullivan CA, Banker GA (1988) The establishment of polarity by hippocampal neurons in culture. J Neurosci 8:1454-1468.

Dubinsky JM (1989) Development of inhibitory synapses among striatal neurons in vitro. J Neurosci 9:3955-3965.

Evers J, Laser M, Sun Y, Xie Z, Poo M (1989) Studies of nerve-muscle interactions in Xenopus cell culture: analysis of early synaptic currents. J Neurosci 9:1523-1539.

Fletcher TL, Cameron P, De Camilli P, Banker G (1991) The distribution of synapsin I and synaptophysin in hippocampal neurons developing in culture. $\mathrm{J}$ Neurosci 11:1617-1626.

Goslin K, Banker G (1991) Rat hippocampal neurons in low density culture. In: Culturing nerve cells (Banker G, Goslin K, eds), pp 251282. Cambridge, MA: MIT Press.

Goslin K, Schreyer DJ, Skene JHP, Banker G (1990) The distribution of GAP-43 during the development of neuronal polarity. J Neurosci 10:588-602.

Hall ZW, Sanes JR (1993) Synaptic structure and development: the neuromuscular junction. Cell 72/Neuron 10[Suppl]:99-121.

Han HQ, Nichols RA, Rubin MR, Bahler M, Greengard P (1991) Induction of formation of presynaptic terminals in neuroblastoma cells by synapsin IIb. Nature 349:697-700.

Hayes BP, Roberts A (1973) Synaptic junction development in the spinal cord of an amphibian embryo: an electron microscope study. Z Zellforsch 137:251-269.

Hinds JW, Hinds PL (1976) Synapse formation in the mouse olfactory bulb: quantitative studies. J Comp Neurol 169:15-40.

Honig MG, Hume RI (1986) Fluorescent carbocyanine dyes allow living neurons of identified origin to be studied in long term cultures. J Cell Biol 103:171-187.

Killisch I, Dotti CG, Laurie DJ, Luddens H, Seeburg PH (1991) Expression patterns of $\mathrm{GABA}_{\mathrm{A}}$ receptor subtypes in developing hippocampal neurons. Neuron 7:927-936.

Kornguth SE, Anderson JW, Scott G (1968) The development of synaptic contacts in the cerebellum of Macaca mulatta. J Comp Neurol 150:169-176.

Lah JJ, Burry RW (1988) Expression and distribution of synaptic vesicle protein SVP65 in cultured dorsal root ganglion neurons. Soc Neurosci Abstr 14:514.

Landmesser L, Pilar G (1972) The onset and development of transmission in the chick ciliary ganglion. J Physiol (Lond) 222:691-713.

Larramendi LMH (1969) Analysis of synaptogenesis in the cerebellum of the mouse. In: Neurobiology of cerebellar evolution and development (Llinas R, ed), pp 803-843. Chicago: AMA Education and Research Foundation.

Loffler F, Lohmann SM, Walckhoff B, Walter U, Hamprecht B (1986) Immunocytochemical characterization of neuron-rich primary cultures of embryonic rat brain cells by established neuronal and glial markers and by monospecific antisera against cyclic nucleotide-dependent protein kinases and the synaptic vesicle protein synapsin I. Brain Res 363:205-221.

Lou X, Bixby JL (1993) Coordinate and noncoordinate regulation of synaptic vesicle protein genes during embryonic development. Dev Biol 159:327-337.

Matteoli M, Takei K, Perin MS, Sudhof TC, De Camilli P (1992) Exoendocytotic recycling of synaptic vesicles in developing processes of cultured hippocampal neurons. J Cell Biol 117:849-861.

Molnar Z, Blakemore C (1991) Lack of regional specificity for connections formed between thalamus and cortex in coculture. Nature 351:475-477.

Nastuk MA, Fallon JR (1993) Agrin and the molecular choreography of synapse formation. Trends Neurosci 16:72-76.

Navone F, Jahn R, Di Gioia G, Stukenbrok H, Greengard P, De Camilli P (1986) Protein p38: an integral membrane protein specific for small vesicles of neurons and neuroendocrine cells. J Cell Biol 103: 2511-2527.

Nelson PG, Fields RD, Yu C, Neale EA (1990) Mechanisms involved in activity-dependent synapse formation in mammalian central nervous system cell cultures. J Neurobiol 21:138-156.

O'Brien RJ, Fischbach GD (1986) Excitatory synaptic transmission 
between interneurons and motoneurons in chick spinal cord cell cultures. J Neurosci 6:3284-3289.

Peng HB, Markey DR, Muhlach WL, Pollack ED (1987) Development of presynaptic specializations induced by basic polypeptide-coated latex beads in spinal cord cultures. Synapse 1:10-19.

Peters A, Palay SL, Webster HD (1991) The fine structure of the nervous system. New York: Oxford UP.

Rees RP, Bunge MB, Bunge RP (1976) Morphological changes in the neuritic growth cone and target neuron during synaptic junction development in culture. J Cell Biol 68:240-263.

Ryan TA, Reuter H, Wendland B, Schweizer FE, Tsien RW, Smith SJ (1993) The kinetics of synaptic vesicle recycling measured at single presynaptic boutons. Neuron 11:713-724.

Selak I, Skaper SD, Varon S (1985) Pyruvate participation in the low molecular weight trophic activity for central nervous system neurons in glia-conditioned medium. J Neurosci 5:23-28.

Shepherd GM (1990) Synaptic organization of the brain. New York: Oxford UP.
Skoff RP, Hamburger V (1974) Fine structure of dendritic and axonal growth cones in embryonic chick spinal cord. J Comp Neurol 153: 107-148.

Van den Pol AN, Kim WT (1993) NILE/L1 and NCAM-polysialic acid expression on growing axons of isolated neurons. J Comp Neurol 332:237-257.

Vaughn JE (1989) Review: fine structure of synaptogenesis in the vertebrate central nervous system. Synapse 3:255-285.

Vaughn JE, Henrikson CK, Grieshaber JA (1974) A quantitative study of synapses on motor neuron dendritic growth cones in developing mouse spinal cord. J Cell Biol 60:664-672.

Weiss S, Pin J-P, Sebben M, Kemp DE, Sladeczek F, Gabrion J, Bodkacrt J (1986) Synaptogenesis of cultured striatal neurons in serumfree medium: a morphological and biochemical study. Proc Natl Acad Sci USA 83:2238-2242.

Xie Z, Poo M-M (1986) Initial events in the formation of neuromuscular synapse: rapid induction of acetylcholine release from embryonic neuron. Proc Natl Acad Sci USA 83:7069-7073. 